\title{
INFECÇÃO CUTÂNEA POR MYCOBACTERIUM HAEMOPHILUM EM DOENTE IMUNODEPRIMIDO
}

\author{
Olga Ferreira',2, Carmen Lisboa ${ }^{1,2}$, Maria João Cruz ${ }^{1,2}$, Joana Sobrinho Simões ${ }^{3}$, Herberto Bettencourt', \\ Filomena Azevedo? \\ 'Serviço de Dermatologia e Venereologia, Centro Hospitalar de São João EPE, Porto, Portugal \\ ${ }^{2}$ Faculdade de Medicina da Universidade do Porto, Porto, Portugal \\ ${ }^{3}$ Serviço de Microbiologia, Centro Hospitalar de São João EPE, Porto, Portugal \\ ${ }^{4}$ Serviço de Anatomia Patológica, Centro Hospitalar de São João EPE, Porto, Portugal
}

RESUMO - A infecção cutânea por Mycobacterium haemophilum é uma patologia rara, de difícil diagnóstico e cujo tratamento constitui um desafio. Descreve-se o caso de um doente sob corticoterapia crónica no contexto de miosite com nódulos dos membros inferiores, nos quais foi detectada uma estirpe de Mycobacterium haemophilum pela técnica de PCR. Este caso enfatiza a necessidade de um alto nível de suspeição clínica para o diagnóstico. De facto, esta infecção pode actualmente estar sub-diagnosticada devido aos requisitos especiais de cultura. Deve ser considerada em doentes com processos granulomatosos crónicos em associação a exame cultural persistentemente negativo.

PALAVRAS-CHAVE - Mycobacterium haemophilum; Micobactéria atípica; Imunossupressão.

\section{MYCOBACTERIUM HAEMOPHILUM SKIN INFECTION IN AN IMMUNOCOMPROMISED PATIENT}

ABSTRACT - Mycobacterium haemophilum skin infection is a rare disease with a difficult diagnosis and a challenging treatment. We report the case of a patient on chronic corticotherapy for myositis with nodules on the lower limbs in which Mycobacterium haemophilum was identified by PCR technique. This case emphasizes the need for a high index of suspicion for the diagnosis. In fact, this infection can currently be underdiagnosed due to the special requirements for culture. It should be considered in patients with chronic granulomatous processes in combination with negative mycobacteriological examination.

KEY-WORDS - Mycobacterium haemophilum; Immunocompromised host; Mycobacterium infections; Skin diseases, bacterial.

\section{Conflitos de interesse: Os autores declaram não possuir conflitos de interesse. \\ No conflicts of interest. \\ Suporte financeiro: $O$ presente trabalho não foi suportado por nenhum subsídio ou bolsa. \\ No sponsorship or scholarship granted.}

Recebido/Received - Junho/June 2012; Aceite/Accepted - Julho/July 2012

\section{Dr. $\mathrm{a}$ Olga Ferreira}

Serviço de Dermatologia e Venereologia

Centro Hospitalar de São João, EPE

Alameda Hernâni Monteiro

4202-451 Porto

Te.l: +351225512193

Fax: +351225512193

E-mail: ocsferreira@gmail.com 


\section{Caso Clínico}

\section{INTRODUCTION}

Mycobacterium is a genus that includes several species, namely $M$. tuberculosis, $M$. leprae and atypical mycobateria. Pinner introduced the latter concept in the 30 s and since then it has gained increasing importance due to human immunodeficiency virus (HIV) infection and the use of immunossuppressors ${ }^{1}$.

Mycobacterium haemophilum was first described in 1978 in a patient with Hodgkin disease ${ }^{2}$. It causes disease in two distinct groups, particularly in immunocompromised adults and immunocompetent children ${ }^{3}$.

\section{CASE REPORT}

A 67-year-old male was observed due to hyperpigmented macules and violaceous to brown papules and nodules (Fig. 1), some of them draining a yellowish exudate on the lower limbs, evolving for more than a year. The patient denied recent travel history however in the past he had traveled to several countries in Africa. He suffered from myositis and cardiovascular disease and was medicated for several years with deflazacort, acenocoumarol, aspirin, amiodarone, digoxin, diltiazem, furosemide, omeprazole and trazodone. Histological examination revealed granulomatous inflammation with central necrosis (Fig. 2). Bacteriological, mycological and mycobacteriological examination were negative.

As new lesions were appearing the patient was submitted again to skin biopsy. Histology was similar to the previous one but this time Ziehl-Neelsen stain revealed the presence of acid-fast bacilli exhibiting cord formation. Tissue culture was negative for bacteria, fungi and mycobacteria. PCR technique was negative for M. tuberculosis but detected a strain of M. haemophilum. The microbiological examination of respiratory secretions was negative and chest $\mathrm{X}$-ray, brain $\mathrm{CT}$ and brain and spine MRI revealed no significant changes.

The diagnosis of $M$. haemophilum skin infection was made and treatment with rifampicin $1600 \mathrm{mg} /$ day), clarithromycin $(500 \mathrm{mg}, 2 \mathrm{id})$ and ciprofloxacin (500mg, 2id) was started. However clarithromycin was suspended two weeks later due to gastrointestinal intolerance.

At three months of treatment (rifampicin and ciprofloxacin) a decrease in the number and size of lesions was noted but ciprofloxacin was suspended due to progressive weight loss and persistent vomiting. Clarithromycin was reintroduced, however a week later the patient stopped it on his own initiative. The patient continued only with rifampicin but three months later new lesions developed. Swab microbiological culture yielded negative results and persistence of $M$. haemophilum was detected by PCR technique. The patient refused reintroduction of clarithromycin or ciprofloxacin.

At six months of treatment with rifampicin the patient was admitted to another hospital due to aspiration pneumonia with favorable response to antibiotic therapy. One month later he was readmitted and died from multiple organ failure.

\section{DISCUSSION}

M. haemophilum infection is a rare disease with less than 300 cases reported in the literature. Many aspects
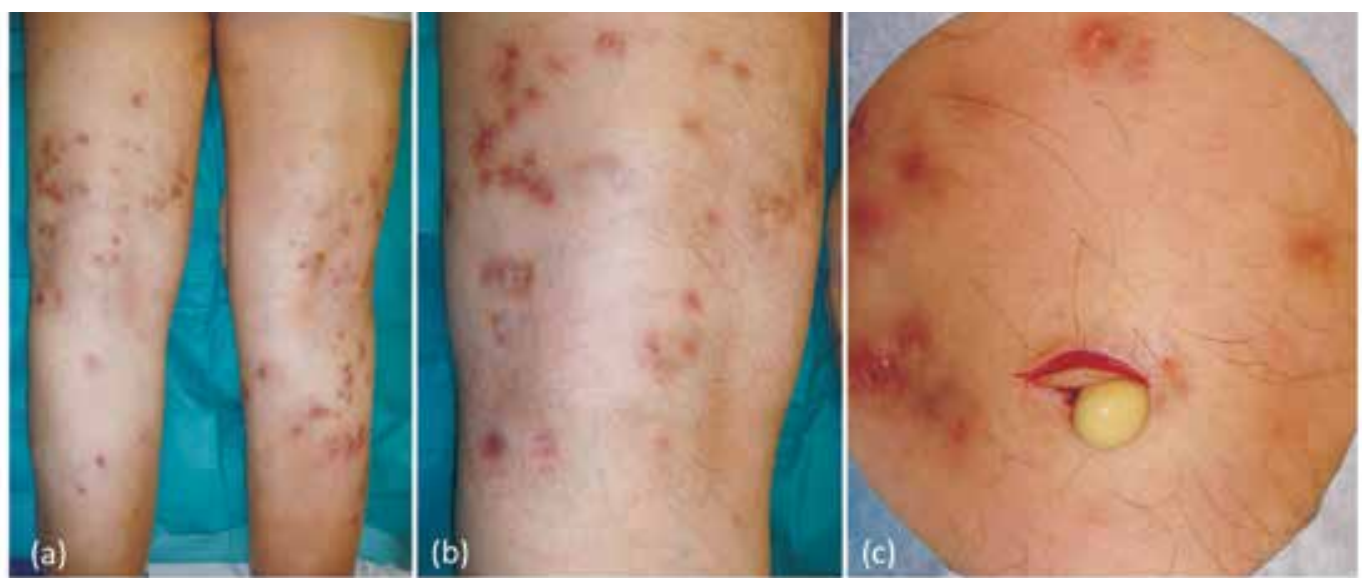

Fig. 1 - Violaceous to brown papules and nodules on the lower limbs (a,b); yellowish exudate during biopsy (c). 


\section{Caso Clínico}

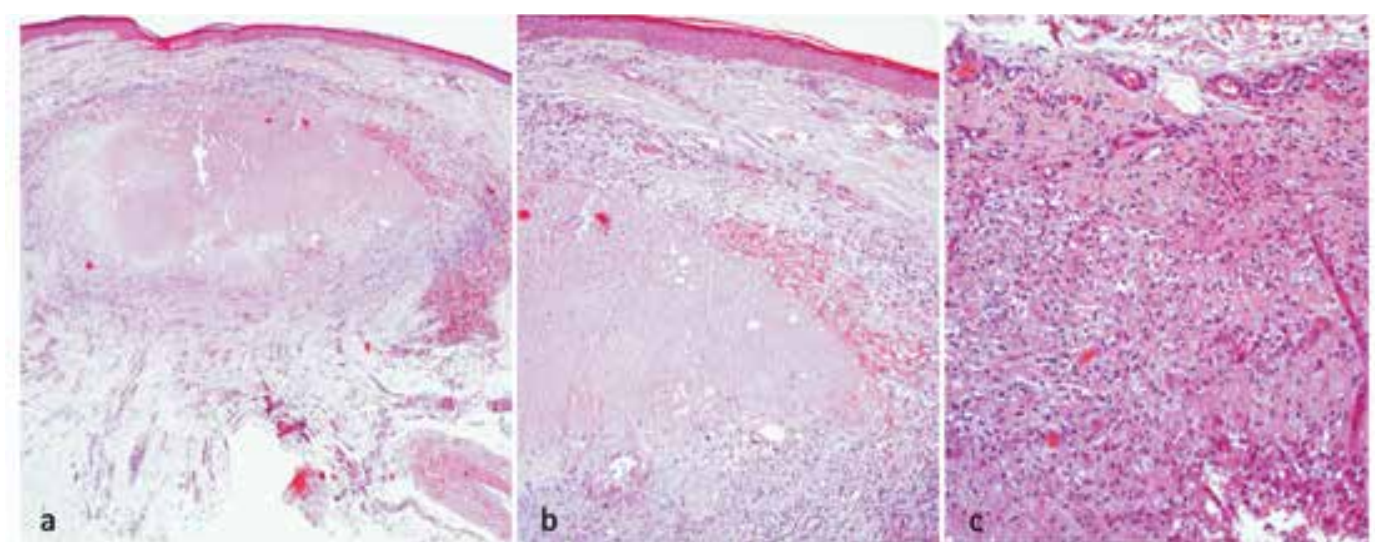

Fig 2 - Granulomatous inflammation with central necrosis (H\&E).

of its epidemiology are still unknown, namely the reservoir and the mode of transmission ${ }^{3,4}$. However an environmental source was suggested due to the absence of reported cases of person to person transmission and variable genetic pattern of isolates in different geographical areas 5 .

M. haemophilum is an acid-fast, aerobic, slow growing bacilli, with preferential temperatures between 30-32 ${ }^{\circ} \mathrm{C}$, which explains its predilection for the extremities $^{5}$. As other atypical mycobacteria usually affects immunocompromised adults, although disease in immunocompetent children and rarely in immunocompetent adults have also been described ${ }^{3,4}$.

This infection has been reported in patients with HIV infection, transplants, hematologic dyscrasias and diseases requiring chronic immunosuppressive therapies $^{3,4,6}$. Cutaneous lesions are the most frequent finding, although septic arthritis, osteomyelitis, pulmonary or disseminated disease may also occur ${ }^{3}$. Cutaneous involvement is characterized by papules, nodules and cysts, that often evolve with suppuration and ulceration, usually affecting the extremities, followed by the trunk and rarely the face ${ }^{3,5}$. Albeit less frequent M. haemophilum infection has been described in immunocompetent adults, namely in association to permanent makeup of the eyebrows and cervical lymphadenitis similar to children ${ }^{7,8}$.

On the other hand immunocompetent children present with cervical, submandibular or perihilar lymphadenopathy. This group has a favorable prognosis and the treatment consists in the surgical excision of the affected lymph node ${ }^{3,6}$. Rare cases of $M$. haemophilum infection have been described in immunocompromised children with identical clinical manifestations to immunocompromised adults ${ }^{9,10}$.
Deep fungal infections and other mycobacterial infections are the most important differential diagnosis. Panniculitis, lymphoma, vasculitis and sarcoidosis are other diseases that should be considered. The diagnosis is the result from the combination of histopathological and microbiological examination.

Histological findings include the presence of granulomatous inflammation with variable foci of necrosis, which can be accompanied by neutrophilic or mixed cellular infiltrates ${ }^{3,4,6}$. Granulomas are not always evident in immunocompromised patients ${ }^{5}$. The Ziehel-Neelsen staining typically reveals numerous acid-resistant bacilli, singly or arranged in cord formation, however in our case this bacilli were observed only in one of the biopsies 5 .

Culturing M. haemophilum takes about 3-5 weeks and is particularly difficult, as noted in our patient in which several attempts were made. This difficulty is due to the exigent requirements for growth in culture, such as temperature between 30 to $32^{\circ} \mathrm{C}$ and the need for iron supplementation ${ }^{4,5}$. In this setting PCR technique is particularly useful because it allows rapid results and earlier onset of treatment which is very important in immunosuppressed patients. However culture remains the gold standard for diagnosis as it allows the identification of the agent and the performance of drug susceptibility testing.

Clinical presentation and the degree of patient immunossupression are the main determinants of treatment. Surgical excision of the affected lymph node is the treatment of choice in immunocompetent children. In immunocopromised patients the reversal of immunosupression and antibiotics are the preferred approach ${ }^{11}$. However in our case corticosteroids withdrawal was not possible and a multiple antibiotic regimen was performed. 


\section{Caso Clínico}

Standard guidelines for the treatment of $M$. haemophilum infection are still missing. Some authors suggest combination of multiple antibiotics for long periods ( 12 to 24 months) $)^{3}$. In respect to in vitro susceptibility testing it was found that the isolates usually exhibit sensitivity to macrolides and rifamycins, while the fluoroquinolones, streptomycin, clofazimine and amikacin exhibit variable activity ${ }^{5}$. Furthermore antibiotics such as isoniazid, ethambutol, tetracyclines, cefoxitin, cotrimoxazole and pyrazinamide are usually inactive ${ }^{5}$.

The most commonly used antibiotics belong to the group of macrolides, fluoroquinolones and rifamycins. Clarithromycin appears to be the most effective drug against $M$. haemophilum ${ }^{5}$. Multiple drug regimen is used to prevent the development of resistances ${ }^{11}$. In fact, cases of resistance to rifamycins are described after several months of treatment ${ }^{12}$. According to Kelley et $a l^{5}$, the initial treatment should include clarithromycin and a rifamycin, and in cases of severe or disseminated disease a fluoroquinolone should be added. This triple combination was our initial choice, however the patient developed severe gastrointestinal intolerance and suspended clarithromycin.

In addition to the importance of multiple antibiotic association to prevent the emergence of resistance, is also very important the compliance to treatment ${ }^{11}$. In fact suspicion of poor compliance was a serious problem in this patient.

Our patient died in another hospital due to multiple organ failure, however an autopsy was not performed. This procedure could have been useful to assess the eventual presence of disseminated disease.

\section{CONCLUSION}

Increased life expectancy of patients with HIV infection and the increasing use of immunosuppressive treatments may lead to a raise in $M$. haemophilum infection in the future. On the other hand, this infection can currently be underdiagnosed. M. haemophilum is a slow-growing nontuberculous mycobacteria with special requirements for growth. This infection should always be considered in patients with chronic granulomatous processes or with numerous acid-fast bacilli in association with persistently negative microbiological examination. In conclusion, this case emphasizes the need of a high index of suspicion of the diagnosis.

\section{REFERENCES}

1. Pinner M. Atypical acid-fast microorganisms. Am Rev Tuberc. 1935;32:424-45.

2. Naveh D, Yankilewitz T, Lagziel A, Sompolinsky D. Skin granulomata caused by a new microorganism (Mycobacterium haemophilum sp. nov.). Harefuah. 1978; 95(1):5-8.

3. Rajpara A, Sri J, Driscoll M. Mycobacterium haemophilum: Cutanoeus nodules in a renal transplant patient. Dermatol Online J. 2010;16(7):3.

4. Lott JP, Werth VP, Kovarik CL. Cutaneous Mycobacterium haemophilum infection in iatrogenically immunocompromised patients without transplantation. J Am Acad Dermatol. 2008;59(1):139-42.

5. Kelley CF, Armstrong WS, Eaton ME. Disseminated Mycobacterium haemophilum infection. Lancet Infect Dis. $2011 ; 11$ (7):571-8.

6. Shah MK, Sebti A, Kiehn TE, Massarella SA, Sepkowitz KA. Mycobacterium haemophilum in immunocompromised patients. Clin Infect Dis. $2001 ; 33(3): 330-7$.

7. Giulieri S, Morisod B, Edney T, Odman M, Genné $D$, Malinverni R, et al. Outbreak of Mycobacterium haemophilum infections after permanent makeup of the eyebrows. Clin Infect Dis. 2011;52(4):48891.

8. Minani TJC, Saubolle MA, Yu E, Sussland Z. Mycobacterium haemophilum as a novel etiology of cervical lymphadenitis in an otherwise healthy adult patient. J Clin Microbiol 2010; 48: 2636-9.

9. Campbell LB, Maroon M, Pride H, Adams DC, Tyler WB. Mycobacterium haemophilum in an immunosuppressed child. Pediatr Dermatol 2006; 23: 481-3.

10. Bosma F, Deckers-Kocken JM, de Graaf SS, Schulin T, Melchers WJ, Hoogkamp-Korstanje JA. Mycobacterium reverse hybridization line-probe assay used to diagnose disseminated Mycobacterium haemophilum infection in a child with acute lymphoblastic leukemia. Eur J Clin Microbiol Infect Dis 2004; 23: 345-7.

11. Klein NC. Mycobacterium haemophilum. Medscape. [Acessed in 15/1/2012].Available from: http://emedicine.medscape.com/article/223133.

12. Bernard EM, Edwards FF, Kiehn TE, Brown ST, Armstrong $D$. Activities of antimicrobial agents against clinical isolates of Mycobacterium haemophilum. Antimicrob Agents Chemother 1993;37: 2323-6. 